\title{
Síndrome Antifosfolipídica: Uma Revisão a Propósito de Três Casos Clínicos
}

\section{Antiphospholipid Syndrome: Report of Three Cases and Review of the Literature}

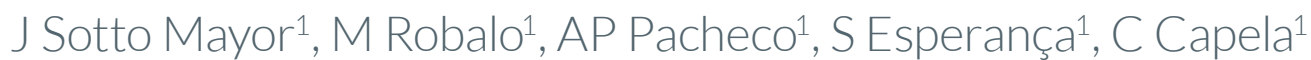

\section{RESUMO}

A síndrome antifosfolipídica é uma doença autoimune e sistémica que se define com base em achados clínicos e laboratoriais, ou seja, presença de tromboses recorrentes, arteriais ou venosas em pessoas jovens, abortos espontâneos recorrentes, trombocitopenia e níveis elevados de anticorpos antifosfolipídeos: anticoagulante lúpico, anticorpos anticardiolipina IgM ou IgG, assim como anticorpos IgM ou IgG anti-beta 2 glicoproteína I e antiprotrombina. Os indivíduos com síndrome antifosfolipídica podem apresentar a síndrome isoladamente, ou em associação a outros distúrbios, nomeadamente autoimunes, sendo o lúpus eritematoso sistémico aquele que dentre todos é o mais comummente associado.

No presente artigo os autores apresentam três casos clínicos nos quais as manifestações trombóticas levaram à investigação de síndrome antifosfolipídica, a qual veio a confirmar-se através de estudo imunológico. A adequação terapêutica permitiu prevenir episódios de recorrência, quando o grau de gravidade dos mesmos o possibilitou.

PALAVRAS-CHAVE: Anticoagulantes; Anticorpos Antifosfolipídeos; Síndrome Antifosfolipídica

\section{ABSTRACT}

The antiphospholipid syndrome is an autoimmune of antiphospholipid antibodies and a systemic disease that is defined based upon clinical and laboratory findings, ie, the presence of recurrent, arterial or venous thrombosis in young people, recurrent spontaneous abortions, thrombocytopenia and elevated antibody levels: lupus anticoagulant, anticardiolipin IgG or IgM antibody, as well as IgM or IgG anti-beta 2-glycoprotein I and antiprothrombin. In individuals with antiphospholipid syndrome, the syndrome may present alone or in association with other disorders, including other autoimmune diseases such as lupus erythematosus, which are among the most commonly associated. In this article the authors present three cases in which the thrombotic manifestations of antiphospholipid syndrome led to the investigation of the diagnosis, which came to be confirmed by immunological study. The use of the right therapeutic prevented episodes of recurrence.

KEYWORDS: Anticoagulants; Antiphospholipid Syndrome; Antibodies, Antiphospholipid 


\section{INTRODUÇÃO}

A síndrome antifosfolipídica (SAF) é um distúrbio autoimune que se caracteriza clinicamente pela ocorrência de tromboses venosas ou arteriais, complicações obstétricas ou ambas; e laboratorialmente pela deteção de trombocitopenia e títulos elevados de anticorpos antifosfolipídicos (AAF): anticoagulante lúpico (AL); anticorpo anticardiolipina (aACL); beta-2 glicoproteína I (B2GPI) e antiprotrombina. ${ }^{1-3}$ Estes foram descritos pela primeira vez em 1906 por Wasserman et al, em doentes que apresentavam resultados positivos nos testes de sífilis. Trata-se de um grupo heterogéneo de anticorpos dirigidos contra as proteínas que unem os fosfolípidos e que se caracteriza por reduzir os tempos de coagulação dependentes dos fosfolípidos. ${ }^{3,4} \mathrm{~A}$ deteção destes anticorpos não significa no entanto que os seus portadores venham a desenvolver SAF, dado terem sido identificados em cerca de $5 \%$ da população saudável. ${ }^{1}$

\section{MÉTODOS}

Foi efetuada uma revisão da literatura recorrendo ao motor de busca PubMed, utilizando como palavras-chave as já referidas. Dos artigos que cumpriram os critérios de seleção, utilizados aqueles que se apresentam nas referências bibliográficas. Foi ainda utilizado o Consenso Internacional de Sydney (2006), para proceder à revisão apresentada.

\section{REVISÃO DA LITERATURA}

A primeira descrição de SAF surgiu em 1983 e postula-se desde então que esta entidade clínica poderá ser o mais comum estado de hipercoagulabilidade adquirido, ocorrendo em mais de $2 \%$ da população geral. ${ }^{1}$ Classicamente classificou-se a síndrome em primária, ou secundária se associada a outras condições clínicas, principalmente o lúpus eritematoso sistémico (LES). ${ }^{4} \mathrm{Na}$ Tabela 1 são expostas as condições clínicas que podem associar-se a SAF. ${ }^{5}$

É importante referir a existência de uma forma particular de SAF, a SAF catastrófica. É uma entidade rara associada a um índice de mortalidade elevado, cerca de 50\%, o qual pode causar, de forma acelerada, falência multiorgânica. ${ }^{1}$ É assim necessário alto nível de suspeição para intervenção em tempo útil. Apesar da mortalidade elevada, afeta apenas $1 \%$ dos doentes com SAF, apresentando esses em comum ${ }^{1}$ :

- Evidência clínica de atingimento de múltiplos sistemas orgânicos, com desenvolvimento num muito curto espaço de tempo;

- Evidência histológica de atingimento de múltiplos vasos sanguíneos de pequeno calibre;
- Confirmação laboratorial da presença de AAF, habitualmente em títulos elevados.

Na maioria dos casos precede-se de um evento desencadeante, frequentemente infeções, mas as neoplasias, cirurgias ou procedimentos invasivos, complicações obstétricas, contracetivos orais ou exacerbações de LES podem desencadear esta forma de SAF. ${ }^{1}$

TABELA 1. Distúrbios associados a SAF.

\begin{tabular}{|c|c|}
\hline Imunológicos & $\begin{array}{l}\text { LES (25-50\%) } \\
\text { Púrpura trombocitopénica idiopática } \\
\text { Artrite reumatoide e psoriática } \\
\text { Síndrome de Sjögren } \\
\text { Arterite de células gigantes/polimialgia } \\
\text { reumática } \\
\text { Distúrbios mistos do tecido conjuntivo } \\
\text { Esclerose sistémica } \\
\text { Doença de Behçet } \\
\text { Poliarterite nodosa } \\
\text { Dermatomiosite/polimiosite } \\
\text { Anemia hemolítica autoimune } \\
\text { Hepatite crónica ativa }\end{array}$ \\
\hline Neoplasias & $\begin{array}{l}\text { Tumores sólidos } \\
\text { Leucemias } \\
\text { Distúrbios linfoproliferativos/linfoma } \\
\text { de Hodgkin } \\
\text { Mieloma múltiplo }\end{array}$ \\
\hline Hematológicos & $\begin{array}{l}\text { Doença de von Willebrand } \\
\text { Mielofibrose } \\
\text { Paraproteinemias }\end{array}$ \\
\hline Infeciosos & $\begin{array}{l}\text { Sífilis } \\
\text { Doença de Hansen } \\
\text { Tuberculose } \\
\text { Mycoplasma } \\
\text { Doença de Lyme } \\
\text { Malária } \\
\text { Sida } \\
\text { Hepatite A e C } \\
\text { Mononucleose } \\
\text { Adenovirose } \\
\text { Parvovirose } \\
\text { Sarampo } \\
\text { Varicela } \\
\text { Endocardite } \\
\text { Sépsis }\end{array}$ \\
\hline Neurológicos & $\begin{array}{l}\text { Miastenia gravis } \\
\text { Esclerose múltipla } \\
\text { Enxaqueca (hemicraniana) }\end{array}$ \\
\hline Fármacos & $\begin{array}{l}\text { Clorpromazina } \\
\text { Fenitoína } \\
\text { Hidralazina } \\
\text { Procainamida } \\
\text { Quinidina } \\
\text { Estreptomicina } \\
\text { Fenotiazina }\end{array}$ \\
\hline
\end{tabular}

Adaptado a partir de Rodríguez Santamaría et al ${ }^{5}$ 
Epidemiologicamente, a frequência de SAF primária na população geral é desconhecida, no entanto acredita-se que a incidência da forma secundária, nas mulheres com LES rondará os 30\% (1 a 20 por cada 100000 mulheres). Os AAF podem apresentar-se em 50\% dos doentes com LES e em 5\% da população saudável. ${ }^{6}$ Ocorre predominantemente em mulheres jovens em idade fértil, raramente se diagnostica em crianças, e com frequência os doentes não ultrapassam a $5^{\text {a }}$ década de vida. No estudo coorte realizado por Pengo et $a^{6}$ a idade média de diagnóstico foi de 34 anos, com predomínio no sexo feminino, sendo a proporção na SAF primária nas mulheres de 1: 3,5, e de 1: 7 na secundária, o que corrobora estudos prévios. $^{7}$

A causa de SAF é ainda desconhecida, no entanto acredita-se ter uma origem multifatorial. Para a sua ocorrência contribui fortemente uma família heterogénea de autoanticorpos contra as proteínas associadas aos fosfolípidos e que são responsáveis de forma direta pela ocorrência de tromboses venosas e arteriais, tal como comprovam vários estudos retrospetivos e prospetivos. ${ }^{8}$ A causa da produção destes anticorpos é também desconhecida, sabendo-se no entanto que interferem na cascata de coagulação e inflamação. Num processo que é mediado pela beta-2 glicoproteína I, os AAF unem-se às plaquetas e às células endoteliais, ativando-as e induzindo um estado procoagulante. ${ }^{1,2}$ A união dos anticorpos estimula ainda o complemento, levando ao recrutamento de outras células inflamatórias, ativação do fator tecidular, lesão endotelial e finalmente trombose. Têm sido propostas várias teorias explicativas deste epifenómeno e que visam esclarecer a tendência à trombose dos doentes com SAF, destacando-se entre elas: a inibição dos fatores da anticoagulação; atividade fibrinolítica lesada; interferência com os fatores de coagulação e complemento; e a ação direta dos AAF sobre a função celular. ${ }^{1}$

A apresentação clínica é variada e pode atingir qualquer órgão ou sistema. De acordo com a respetiva ordem de gravidade, as diferentes manifestações clínicas foram associadas em grupo vermelho e amarelo (Tabela 2), as quais uma vez identificadas devem motivar a investigação de SAF.1

De todas as manifestações clínicas, a trombose venosa profunda dos membros, associada ou não a embolia pulmonar, é segundo os critérios do Consenso Internacional de Sidney, a mais comum, embora qualquer parte da circulação venosa ou arterial possa estar envolvida, nomeadamente a nível dos vasos retinianos, intracranianos, mesentéricos e portais, os quais sofrem trombose mais frequentemente em contexto de SAF. ${ }^{1}$ No que diz
TABELA 2. Manifestações clínicas.

\section{Grupo vermelho}

- Trombose venosa profunda de causa inexplicável ou embolismo pulmonar em pessoas com menos de 50 anos Enfarte do miocárdio em pessoas com menos de 50 anos Ataques isquémicos transitórios em pessoas com menos de 50 anos

- Tromboses recorrentes

Tromboses em localizações atípicas

Perdas fetais inexplicáveis após a $10^{a}$ semana de gestação

Pré-eclampsia severa ou precoce

Atraso severo do crescimento intrauterino

Pré-eclampsia com trombocitopenia severa associada

Cardiopatia valvular

Diagnóstico de lúpus eritematoso sistémico

Grupo amarelo

- Livedo reticular

- Fenómeno de Raynaud

- Trombocitopenia persistente e inexplicada

- Perdas fetais precoces ou abortos de repetição

Adaptado a partir de Cohen et al ${ }^{6}$

respeito às manifestações arteriais trombóticas, a mais comum associa-se a enfarte isquémico, podendo também verificar-se enfarte do miocárdio, gangrena periférica e oclusão de vasos arteriais. ${ }^{1} \mathrm{O}$ atingimento cerebral é também comum, tendo já sido também associada à presença de AAF a isquemia cerebral; a disfunção cognitiva; as convulsões; a coreia; a psicose; a depressão ou o Guillian-Barré. A associação entre valvulopatia cardíaca e manifestações do sistema nervoso central no curso de SAF é sugerida no estudo de Koniari et al, em que êmbolos provenientes da existência de valvulopatias podem causar embolia cerebral com tradução clínica de acordo com o território atingido. ${ }^{1}$

\section{CASOS CLÍNICOS}

\section{CASO 1}

Doente de 26 anos, sexo feminino, encaminhada para a consulta de Medicina Interna para investigação etiológica de acidente vascular cerebral (AVC) isquémico no território distal e cortical da artéria cerebral média esquerda (ACME). Como antecedentes pessoais: trombose venosa profunda (TVP) dois anos antes ao AVC, que motivaram terapêutica inicial com enoxaparina seguida de 5 meses de varfarina. Como medida adicional, suspendeu o anticoncecional oral. Considerando o evento e os antecedentes da doente pediu-se estudo imunológico que revelou: positividade dos aACP IgM ou IgG e do AL. O diagnóstico ficou definitivamente estabelecido com a manutenção da positividade dos respetivos marcadores 
12 semanas após o primeiro doseamento. Verificaram-se, ainda, títulos positivos de anticorpos antinucleares e anti-histonas; presença de imunocomplexos circulantes; C3 e C4 próximos do limite inferior da normalidade; e anti-Ds-DNA negativos. Assim, para além da confirmação de SAF ponderou-se a possibilidade da doente apresentar primariamente LES, o qual se tornou pouco provável pela inexistência de clínica compatível. Desde então, a doente encontra-se hipocoagulada com varfarina, mantendo-se assintomática, sem novos eventos trombóticos.

\section{CASO 2}

Doente de 31 anos, sexo masculino, internado no serviço de Medicina Interna por tromboembolismo pulmonar (TEP) maciço. Apesar da existência de disfunção miocárdica direita confirmada por ecocardiograma, favorecendo a realização de trombólise, optou-se por iniciar hipocoagulação com varfarina. Adicionalmente, o doente apresentava trombocitopenia de 109000 plaquetas. Como fatores de risco trombótico: hipertensão arterial (HTA), obesidade e dislipidemia. Como antecedentes familiares de relevo: pai com episódio de TVP, na sequência de fratura de membro inferior. Durante o internamento foi feita a janela terapêutica necessária ao início da hipocoagulação com varfarina, mantendo-se o doente nesse período sob administração de heparina. Aproveitou-se ainda esse período para realização de estudo de trombofilia hereditária, que se revelou negativo. No seguimento feito em consulta foi pedido estudo imunológico, o qual revelou títulos positivos de anticoagulante lúpico e de anti-beta-2 glicoproteína I. A hipocoagulação com varfarina foi iniciada desde então e o diagnóstico estabelecido após positividade dos mesmos marcadores 15 semanas após o primeiro doseamento. $\bigcirc$ doente mudou também o seu estilo de vida, possibilitando maior controlo dos fatores de risco trombóticos. Através das medidas instituídas o doente manteve-se sem recorrências, encontrando-se desde então assintomático.

\section{CASO 3}

Doente de 20 anos, sexo feminino recorreu ao Serviço de Urgência por sintomas gerais: prostração, astenia e adinamia. Ao exame objetivo era visível palidez mucocutânea, gânglios linfáticos palpáveis a nível cervical e axilar de características inflamatórias. Auscultação cardíaca com sopro sistólico.

O estudo analítico revelou: anemia hemolítica Coombs positiva; D-dímeros elevados e trombocitopenia.

A posteriori verificou-se positividade para anticorpos anti-Ds-DNA, antinucleares de 1: 1280 e anti-RNP positivo. No ecocardiograma: trombo intracardíaco de grandes dimensões e derrame pericárdico de grande volume.
Dado reunir critérios de lúpus eritematoso sistémico, iniciou bólus de altas doses de metilprednisolona e programou-se início de plasmaferese. No entanto, a doente faleceu cerca de 36 horas após a sua admissão em choque cardiogénico.

O exame necrópsico revelou numerosos trombos de fibrina nos capilares, sobretudo glomerulares e medulares, mas também a nível pulmonar e miocárdio. Portanto, lesões de glomerulonefrite lúpica mesangioproliferativa classe Il e micro enfartes miocárdicos.

Os critérios mais que suficientes e LES associados às alterações observadas no exame necrópsico de múltiplos trombos de fibrina a nível dos capilares de vários órgãos, permitiu concluir ter-se tratado de caso de SAF catastrófica seronegativa associada a LES.

\section{DISCUSSÃO}

O diagnóstico de SAF, de acordo com o Consenso Internacional de Sydney (2006)9 , é confirmado pela presença de pelo menos um critério clínico e um laboratorial, ambos expressos na Tabela 3.

As provas de coagulação utilizadas para detetar o anticoagulante lúpico incluem: tempo de tromboplastina parcial ativada; prova do veneno de víbora de Russell; tempo de coagulação de Kaolín; prova de inibição de tromboplastina tecidular. ${ }^{1}$ Outros achados laboratoriais (presença de anticorpos antifosfatidil-serina, antifosfatidil-etanolamina, anti-beta-2 glicoproteína I Ig A, entre outros) são frequentes em doentes com SAF, no entanto não são específicos, pelo que não fazem parte dos critérios de diagnóstico, reconhecendo-se no entanto a sua associação à doença. ${ }^{1,4}$

No que diz respeito ao tratamento, este é estratificado de acordo com o risco trombótico de SAF, não sendo linear o ajuste da intensidade e duração ótimas da anticoagulação no sentido de prevenir recorrências trombóticas. As condutas terapêuticas ajustam-se de acordo com o evento associado a SAF, ou seja, trombose venosa; trombose arterial; e SAF obstétrica. ${ }^{1,3}$ Estes esquemas visam um INR padrão e são expressos na Tabela 4.

A trombose venosa é de todas, a manifestação mais frequente. O tratamento na fase aguda não difere do aplicado nos casos de trombose em evento não agudo, ou seja, heparina de baixo peso molecular (HBPM) em doses terapêuticas durante 5 dias, alterada após esse período para anticoagulação oral (antagonistas da vitamina $\mathrm{K}$ varfarina) em doses moderadas (INR 2-3), reduzindo-se assim a recorrência de trombose em 80-90\%.4 Para o tratamento a longo prazo elege-se a anticoagulação oral em doses moderadas (INR 2-3), o que comparativamen- 
TABELA 3. Critérios de diagnóstico de síndrome antifosfolipídica (SAF).

\section{Critérios Clínicos Trombose vascular \\ - Trombose arterial, venosa ou de pequeno vaso em qual- quer órgão ou tecido, confirmada com métodos objetivos. Histologicamente: trombose sem presença de inflamação \\ Complicações na gravidez \\ - Uma ou mais mortes fetais inexplicadas após a $10^{a}$ sema- na de gestação com feto normal, sendo a morfologia fetal documentada por ecografia ou exame direto do feto \\ - Um ou mais nascimentos prematuros de neonatos morfo- logicamente normais até à $34^{a}$ semana gestacional devido a pré-eclampsia severa, eclampsia ou insuficiência placentar \\ Três ou mais abortos espontâneos consecutivos e inexpli- cados antes da $10^{a}$ semana de gestação, na ausência de anomalias anatómicas ou hormonais maternas ou altera- ções genéticas dos progenitores}

\section{Critérios Laboratoriais}

- Presença no plasma de anticoagulante lúpico em duas determinações separadas por um período mínimo de 12 semanas, detetado segundo as normas da Sociedade Internacional de Trombose e Hemostasia

- Deteção por métodos de ELISA de títulos moderados a altos de anticorpos anticardiolipina (> 40 unidades de fosfolípido IgG ou lgM [1 unidade é equivalente a $1 \mathrm{mcg}$ de anticorpo], ou > ao percentil 99) dos isotipos IgG ou IgM em duas determinações separadas por um período mínimo de 12 semanas

- Deteção por métodos de ELISA de títulos moderados a altos de anticorpos anti-beta-2 glicoproteína I (>40 unidades de fosfolípido ou > ao percentil 99) dos isótopos lgG ou IgM em duas determinações separadas por um período mínimo de 12 semanas

Adaptado a partir de Miyakis et al ${ }^{8}$

te à terapêutica em altas doses (INR >3) consegue reduzir francamente as complicações hemorrágicas. ${ }^{4}$ Não está estabelecida a duração do tratamento, mas idealmente a anticoagulação não deve ser nunca suspensa. ${ }^{4}$

Relativamente à trombose arterial, esta atinge sobretudo a circulação cerebral, manifestando-se maioritariamente como ictus isquémico. A terapêutica recomendada nestes casos é preferencialmente a anticoagulação oral em doses moderadas e, na sua contraindicação, a antiagregação com aspirina. ${ }^{4}$

Nos casos de gravidez, para as mulheres que têm AAF e perdas fetais, preconiza-se a combinação de HBPM em doses profiláticas por via subcutânea com aspirina (80$100 \mathrm{mg} / \mathrm{dia}) .{ }^{10} \mathrm{O}$ tratamento deve iniciar-se assim que seja documentada a gravidez e manter-se até ao final da mesma. No caso de mulheres grávidas com história de trombose, em tratamento prévio com anticoagulantes orais, estes devem substituir-se por HBPM em doses terapêuticas, administrada ao longo de toda a gestação, reiniciando-se a anticoagulação oral após o parto.10,11
No que diz respeito ao tratamento da SAF catastrófica, este constitui ainda um grande desafio dada a inexistência de regime terapêutico ótimo. De acordo com a maior evidência atual, esse baseia-se na combinação de anticoagulantes orais, esteroides e plasmaferese ou imunoglobulina endovenosa. Ainda sem benefício comprovado têm sido utilizados agentes fibrinolíticos. ${ }^{12}$

Adicionalmente às medidas terapêuticas deve incentivar-se os doentes a adotar um estilo de vida que favoreça a correção de fatores de risco clássicos para trombofilia, entre eles: hipertensão; tabagismo; hipercolesterolemia e diabetes mellitus. É aconselhável ainda a suspensão da toma de contracetivos orais que contenham estrogénio. ${ }^{1}$

\section{CONCLUSÃO}

A SAF representa um estado de hipercoagulabilidade adquirido mediado por anticorpos que predispõem ao aparecimento de complicações trombóticas. O diagnóstico baseia-se em grande medida numa alta suspeição clínica confirmada a partir dos achados laboratoriais, daí que a presença de tromboses venosas ou arteriais recorrentes, ou a sua ocorrência em doentes sem fatores de risco associados deva levar à investigação de SAF. O tratamento baseia-se em medidas de profilaxia antitrombóticas e controlo dos fatores de risco associados.

Apesar dos progressos a nível do conhecimento sobre a patogénese da doença mantêm-se as dificuldades na previsão de quais os doentes com risco de desenvolvimento de complicações tromboembólicas.

Falta por isso alcançar muitos objetivos no que diz respeito à intervenção sobre esta entidade clínica, nomeadamente a nível do rápido reconhecimento e consequente investigação, e que visam a prevenção de complicações e recorrência dos episódios.

CONFLITOS DE INTERESSE: Os autores declaram não ter qualquer conflito de interesse na realização do presente trabalho.

PROTEÇÃO DE PESSOAS E ANIMAIS: Os autores declaram que os procedimentos seguidos na elaboração do presente trabalho estão em conformidade com as normas das comissões de investigação clínica e de ética, bem como da declaração de Helsínquia e da Associação Médica Mundial.

FONTES DE FINANCIAMENTO: Não houve qualquer fonte de financiamento na realização do presente trabalho.

CONFIDENCIALIDADE DOS DADOS: Os autores declaram ter seguido os protocolos da sua instituição acerca da publicação de dados de doentes. 
TABELA 4. Tratamento de SAF.

\begin{tabular}{|c|c|}
\hline & Recomendações \\
\hline Primeira trombose venosa profunda & TAO (INR= 2-3) Manutenção de tratamento a longo prazo \\
\hline Primeiro ictus & TAO (INR= 2-3) Indefinidamente, alternativamente aspirina (300 mg/dia) \\
\hline Primeira trombose arterial ou cerebral & TAO (INR= 2-3) Isoladamente ou combinado com aspirina (100 mg/dia) \\
\hline Trombose recorrente apesar do tratamento & Desconhece-se tratamento ótimo TAO (INR > 3) ou doses terapêuticas de HBPM \\
\hline Na gravidez & Recomendações \\
\hline SAF com trombose e anticoagulação & $\begin{array}{l}\text { Substituir TAO por HBPM em dose terapêutica antes da gestação; } \\
\text { reiniciar TAO no pós-parto }\end{array}$ \\
\hline $\begin{array}{l}\text { SAF sem trombose com perdas fetais } \\
\text { recorrentes tardias }\end{array}$ & $\begin{array}{l}\text { Sem evidência inequívoca } \\
\text { Combinação de HBPM e aspirina durante a gravidez }\end{array}$ \\
\hline $\begin{array}{l}\text { SAF sem trombose com perdas fetais } \\
\text { recorrentes precoces }\end{array}$ & $\begin{array}{l}\text { Sem evidência inequívoca } \\
\text { Combinação de HBPM e aspirina durante a gravidez }\end{array}$ \\
\hline SAF sem trombose nem perdas fetais & $\begin{array}{l}\text { Desconhece-se o tratamento ótimo } \\
\text { Abstenção terapêutica, doses baixas de aspirina ou profiláticas de HBPM }\end{array}$ \\
\hline
\end{tabular}

TAO tratamento anticoagulante oral; INR razão normalizada internacional; HBPM heparina de baixo peso molecular.

\section{REFERÊNCIAS}

1. Pubiliones P, Brooks Y, Brooks I. Syndrome of antiphospholipid antibodies. MEDISAN. 2012;16:429-444.

2. Contreras M. Inmunopatogenia del síndrome antifosfolípido. Rev Chil Reumatol. 2009;25:149-55.

3. Lim W. Antiphospholipid syndrome. Hematology Am Soc Hematol Educ Program. 2013;2013:675-60.

4. Páramo JA, García R, Rodríguez P, Panizo E, Lecumberri R. Tratamiento del síndrome antifosfolípido. Rev Med Univ Navarra. 2007;51:38-41.

5. Rodríguez Santamaría J, Badziak D, Ferreira de Barros M, Luiz Mandelli F, Cavalin LC, Shigueru Sato M. Síndrome antifosfolípido. An Bras Dermatol. 2005;80:3-4.

6. Pengo V, Ruffatti A, Legnani C, Gresele P, Barcellona D, Erba N, et al. Clinical course of high risk patients diagnosed with antiphospholipid syndrome (APS). J Thromb Haemost. 2010;8:237-42.

7. Cohen D, Berger SP, Steup-Beekman GM, Bloemenkamp KW, Bajema IM. Diagnosis and management of the antiphospholipid syndrome. BMJ. 2010;340:2541.
8. Giannakopoulos B, Passam F, Rahgozar S, Krilis AS. Current concepts on the pathogenesis of the antiphospholipid syndrome. Blood. 2007;109:422-30.

9. Miyakis S, Lockshin MD, Atsumi T, Branch DW, Brey RL, Cervera $\mathrm{R}$, et al. International consensus statement on an update of the classification criteria for definite antiphospholipid syndrome (APS). J Thromb Haemostat. 2006:4:295-306.

10. Lim W, Crowther MA, Eikelboom JW. Management of antiphospholipid syndrome: A systematic review. JAMA. 2006;295:1050-7.

11. Salmon JE, Girardi G, Lockshin MD. The antiphospholipid syndrome as a disorder initiated by inflammation: implications for the therapy of pregnant patients. Nat Clin Pract Rheumatol. 2007;3:140-7.

12. Asherson RA. The catastrophic antiphospholipid (Asherson's syndrome) in 2004- a review. Autoimmune Rev. 2005;4:48-54. 